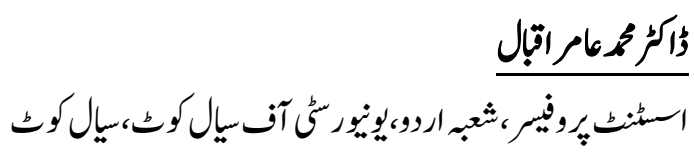

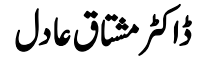

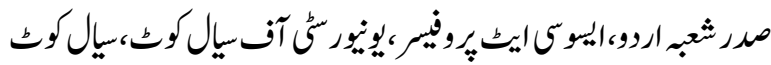
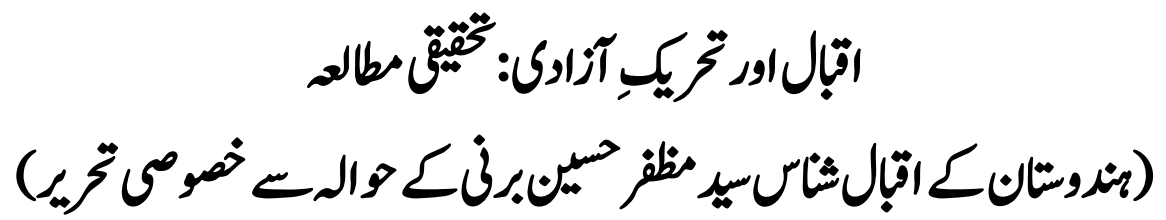

Dr. Muhammad Amir Iqbal

Assistant Professor. Department of Urdu, University of Sialkot.

Dr. Mushtaq Adil

Head Department of Urdu, Associate Professor, University of

Sialkot.

\title{
Iqbal and the Freedom Movement: A Research Study (Special article with reference to Indian Iqbal Scholar Syed Muzafar Hussain Burni)
}

Muzaffar Hussain Burni was a well-known name in Iqbal Studies in India. He has held many high government positions. His services to Iqbal Studies are invaluable. He is the founder of Iqbal Academy (India) Delhi. This article will cover aspects of Mr. Burni's intellectual and political insights. He has also shed light on the personalities of Iqbal and Gandhiji. The great tragedy of Jallianwala Bagh was the subject. The political situation of this period is also part of this article. Mr. Burni described Iqbal's ideas. The center of Iqbal's thinking was unity. The book published on these topics is a witness to Mr. Burni's scholarly thinking. He arranged Iqbal's letters in chronological order and preserved them in four volumes. His knowledge of Iqbal opens up new avenues for research.

Keywords: Iqbal and national unity in the light of Burni's Iqbal studies.

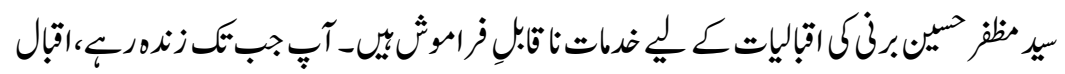

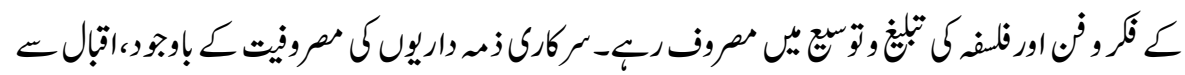




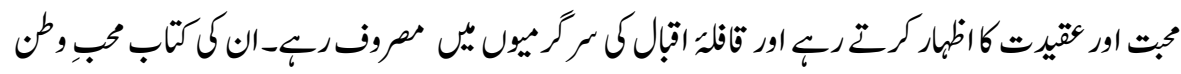

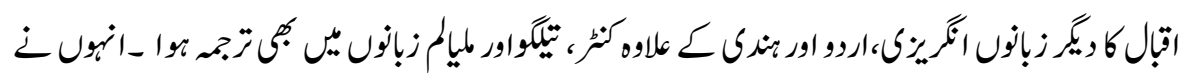

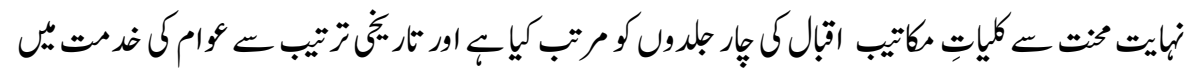

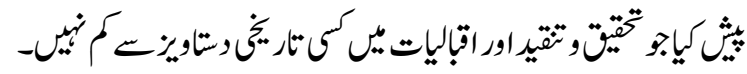

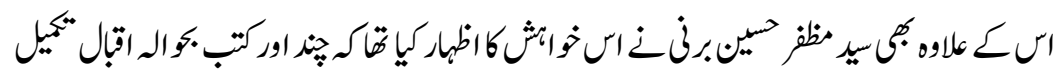

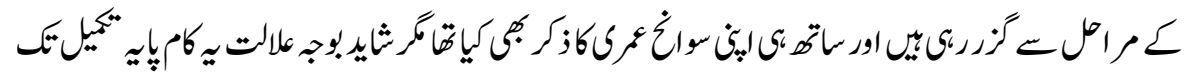

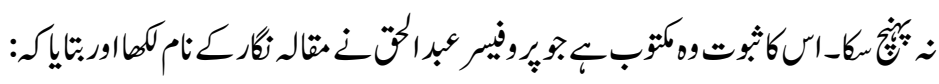

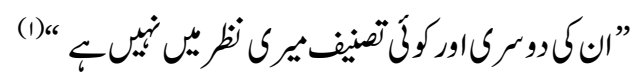

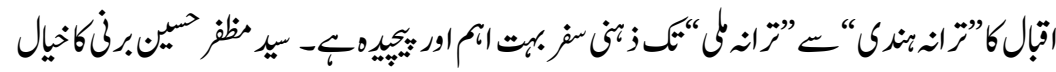

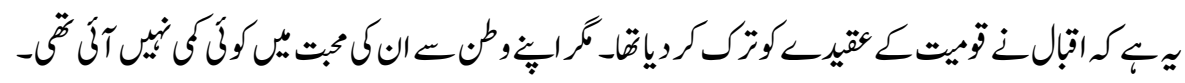

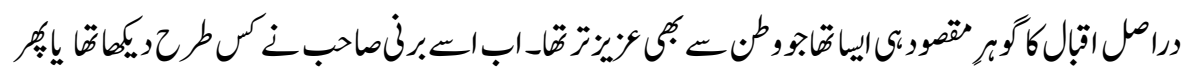

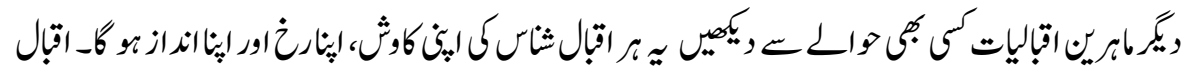

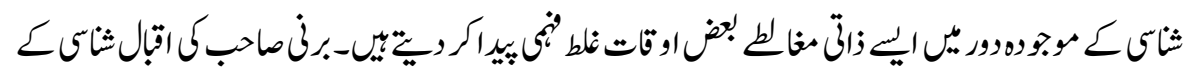

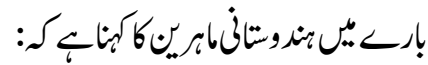

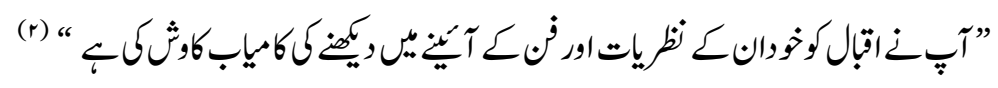

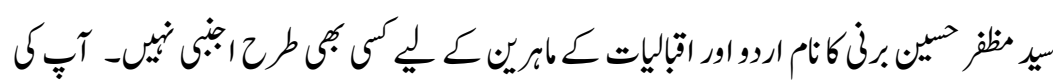

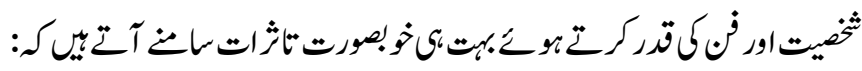

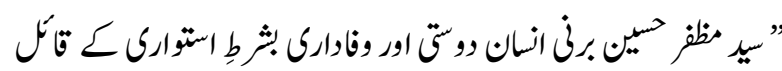

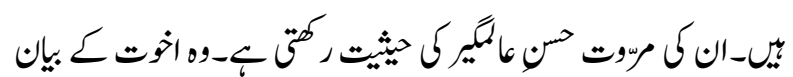

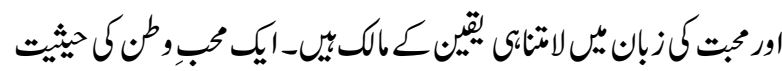

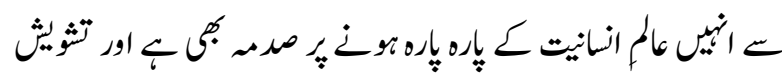

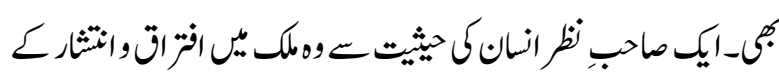




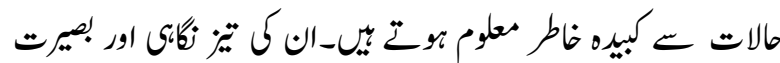

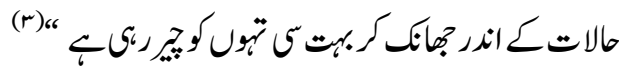

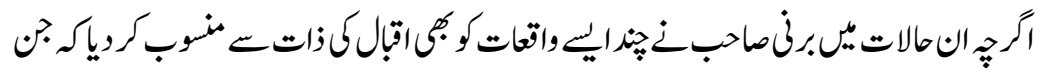

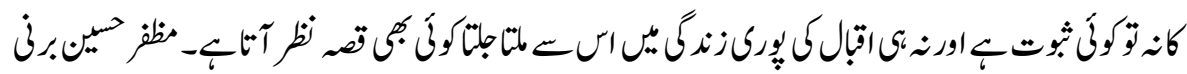

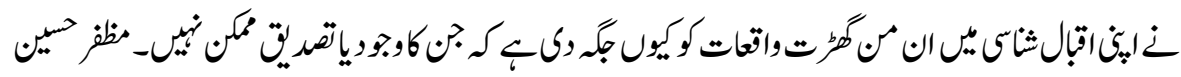

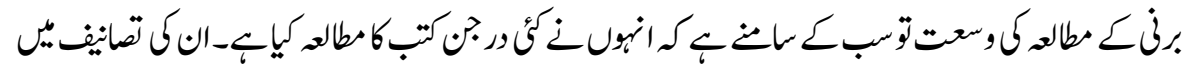

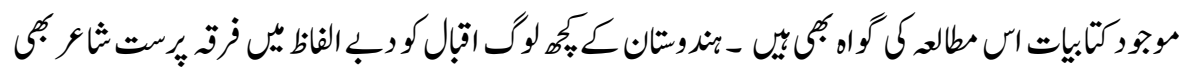

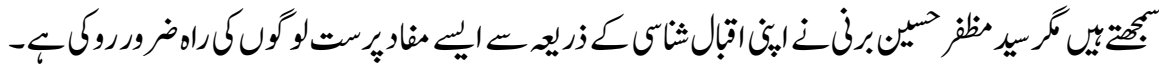

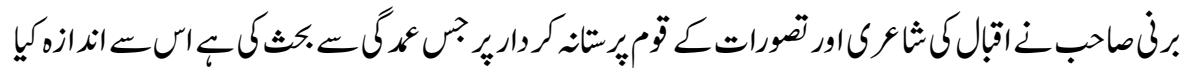

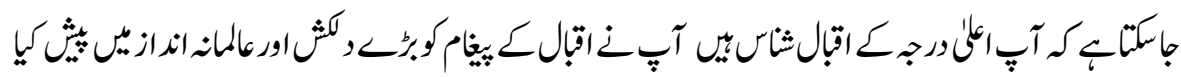

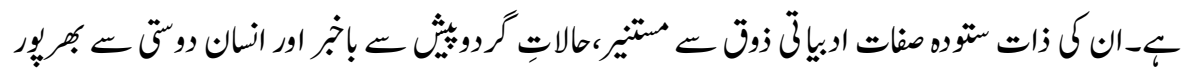

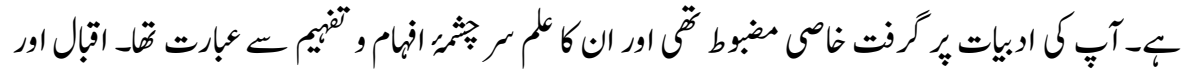

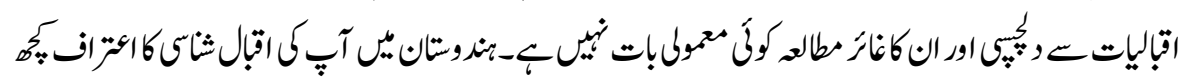

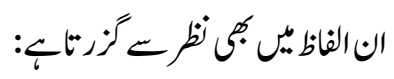

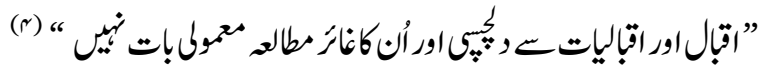

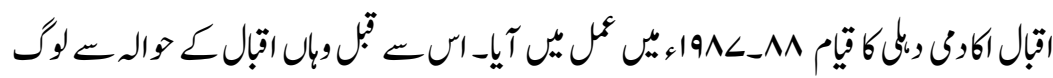

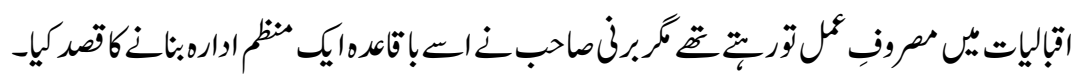

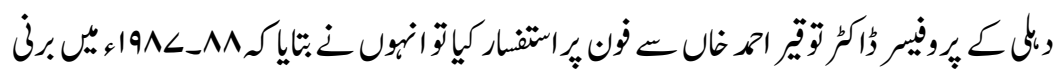

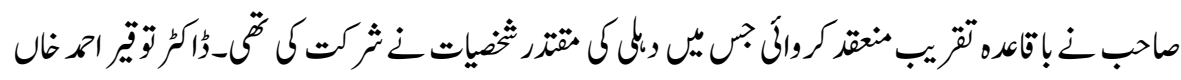

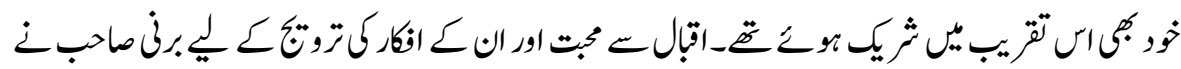

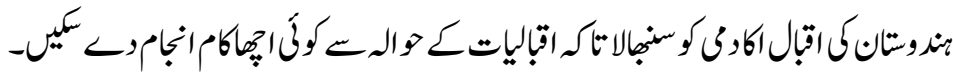




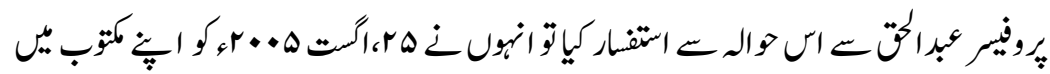

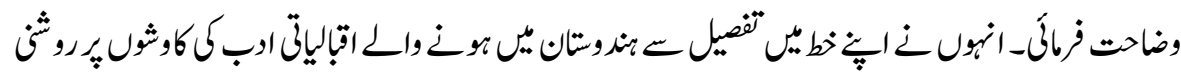

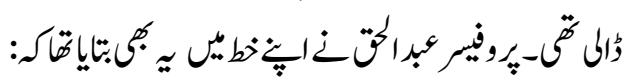

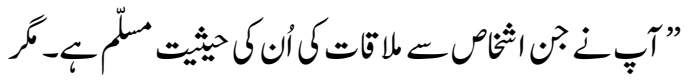

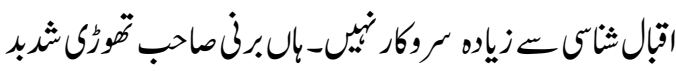

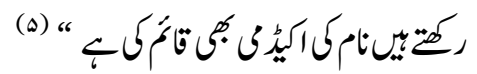

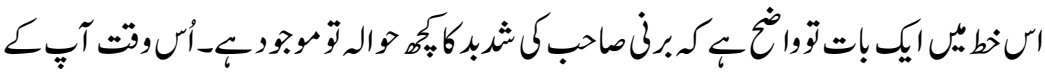

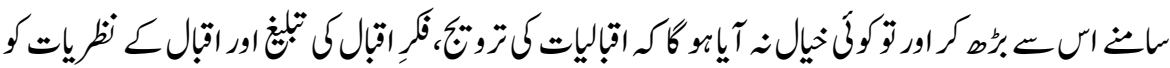

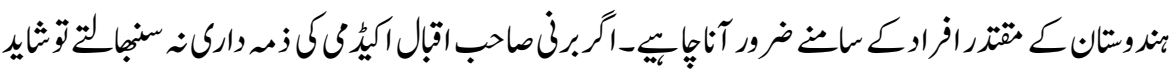

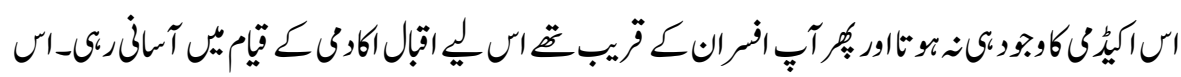

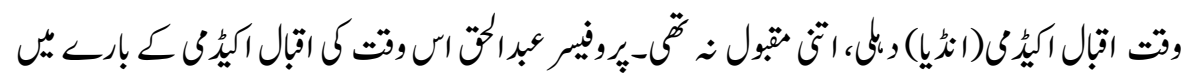
زماتحيّ:

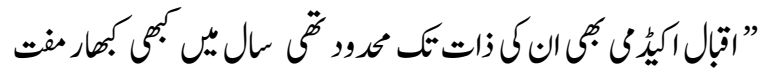

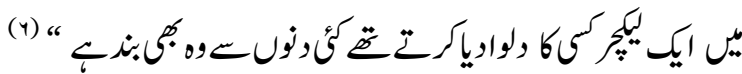

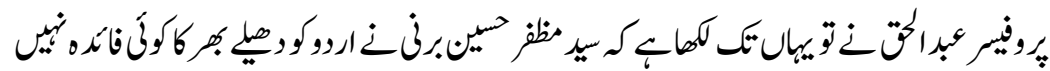

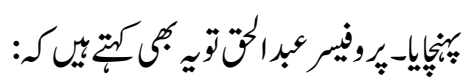

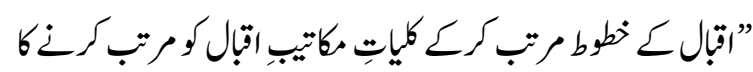

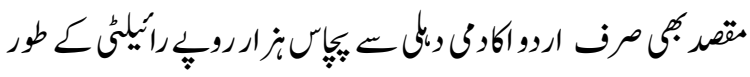

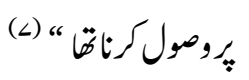

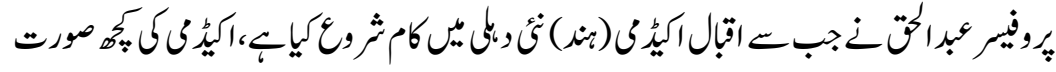

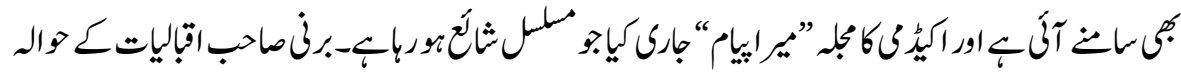

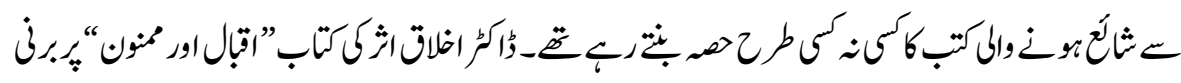

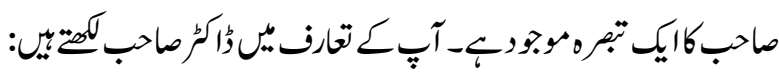




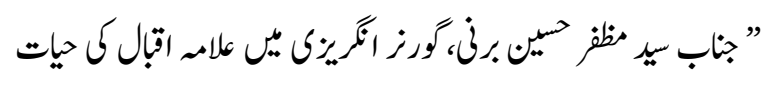

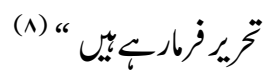

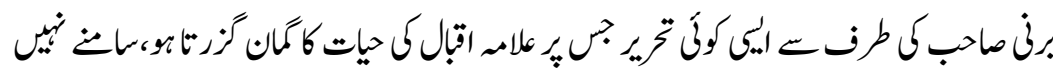

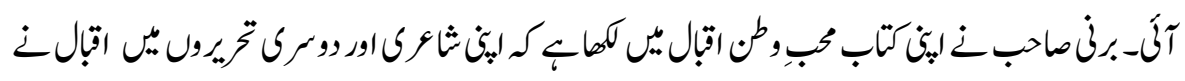

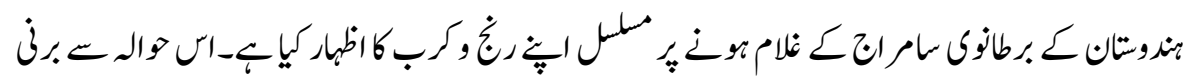

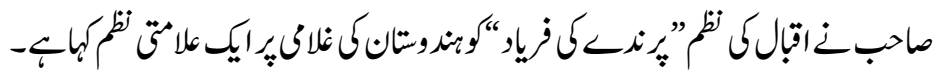

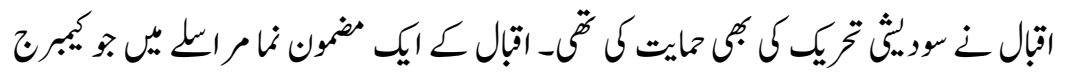

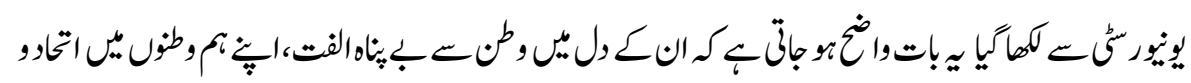

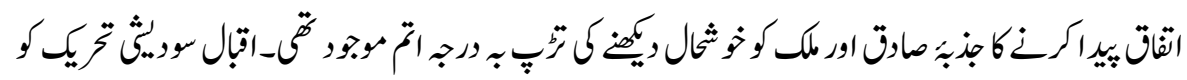

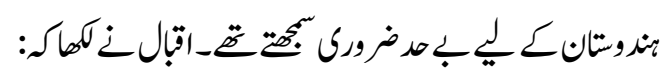

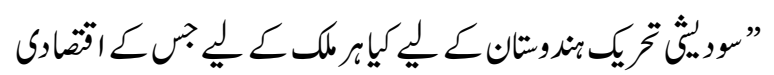

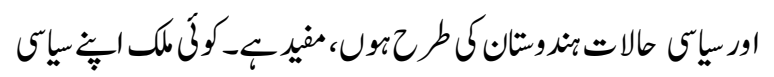

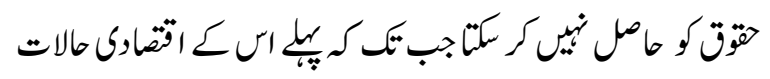

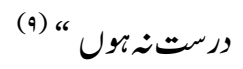

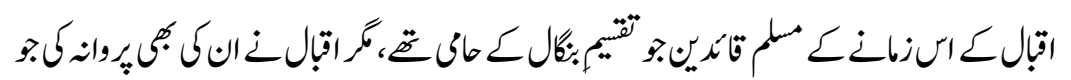

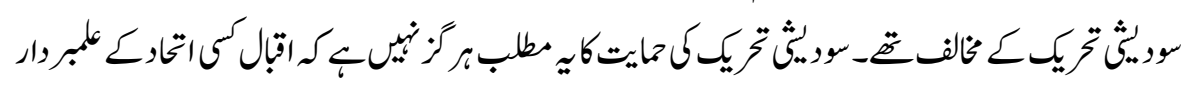

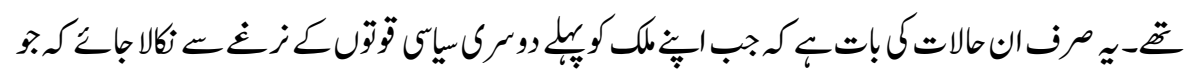

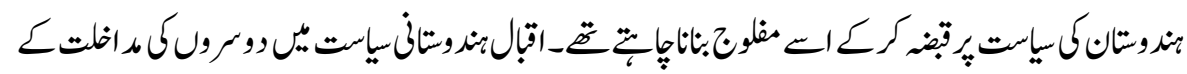

$$
\text { شيرخافـت }
$$

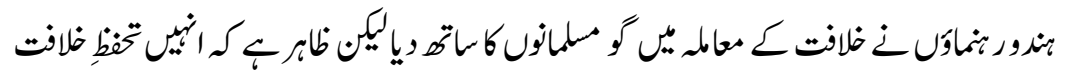

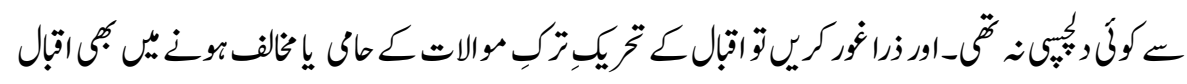

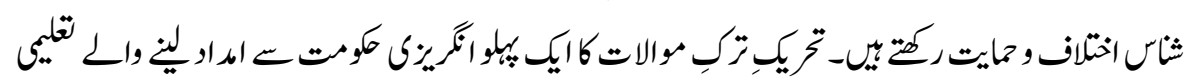

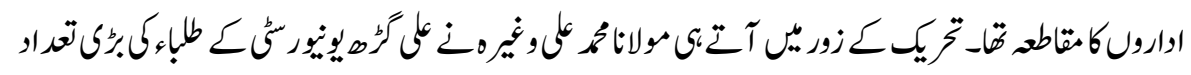




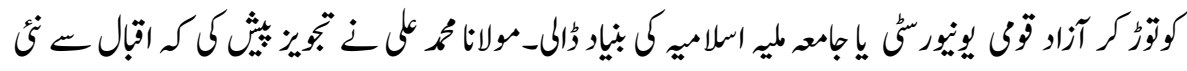

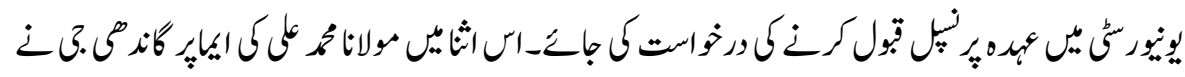

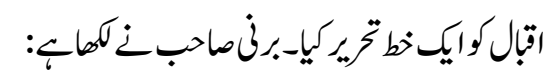

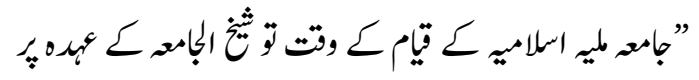

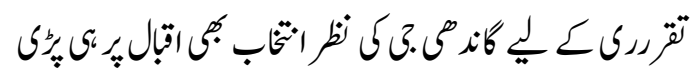

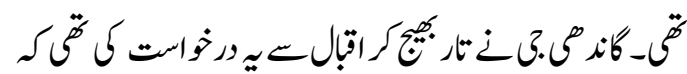

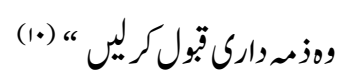

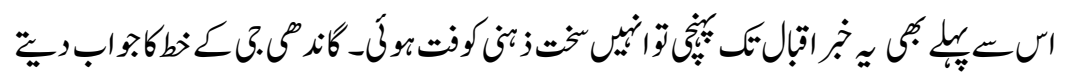

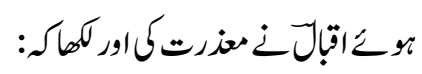

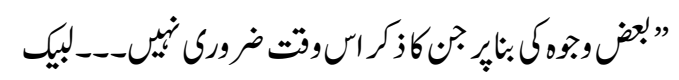

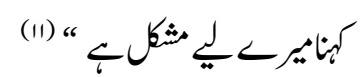

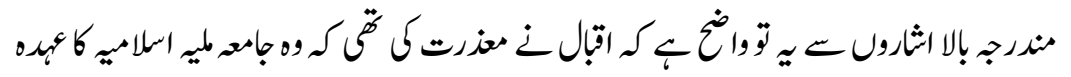

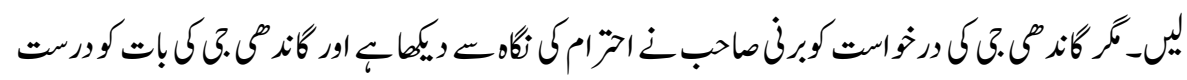

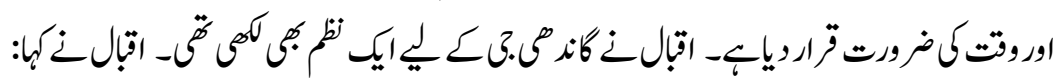

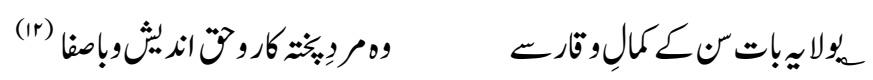

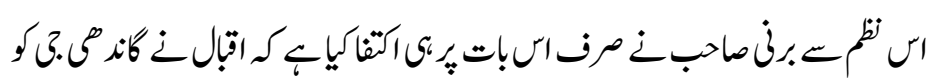

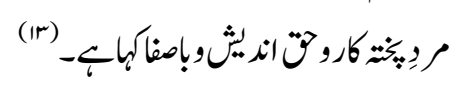

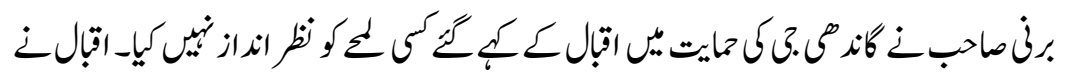

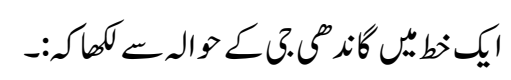

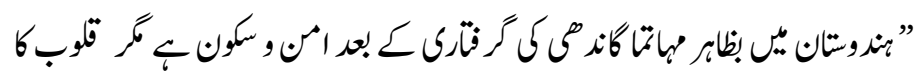

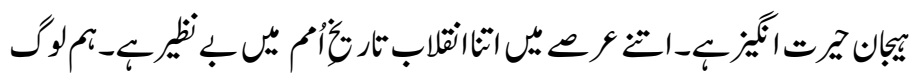

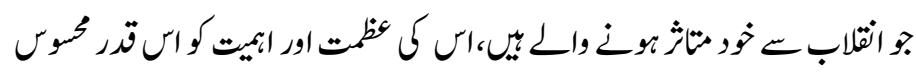

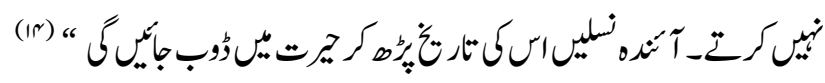




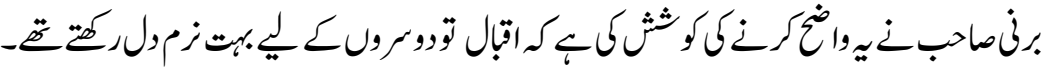

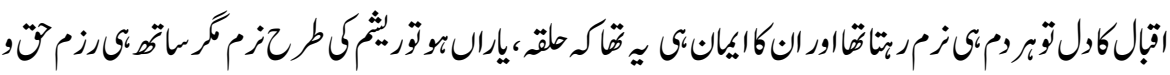

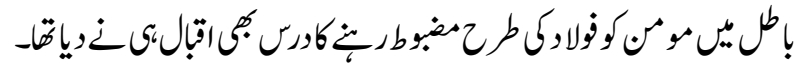

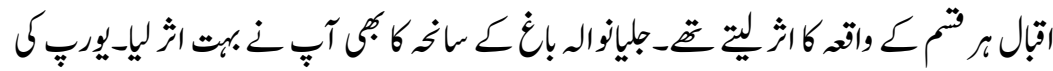

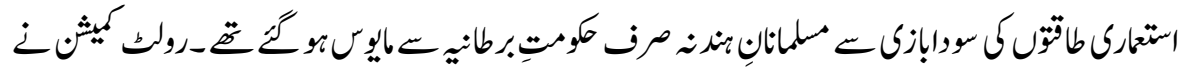

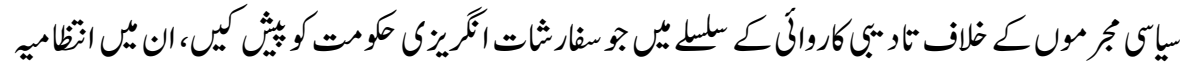

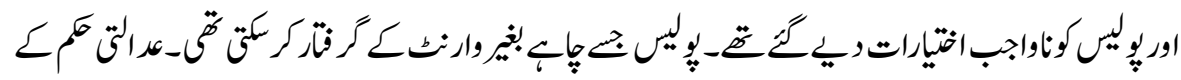

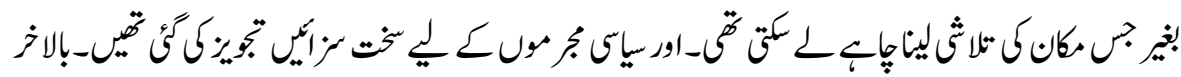

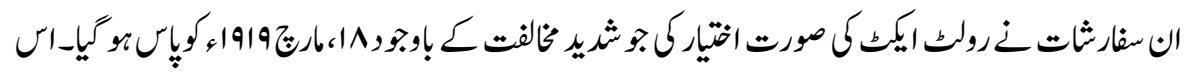

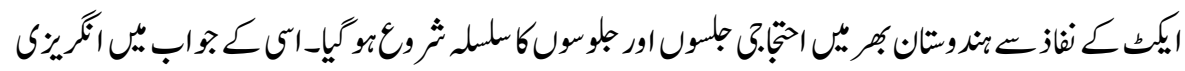

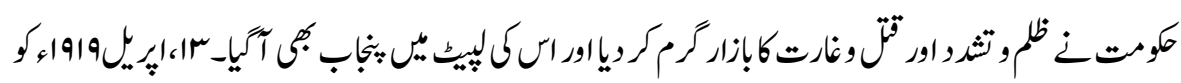

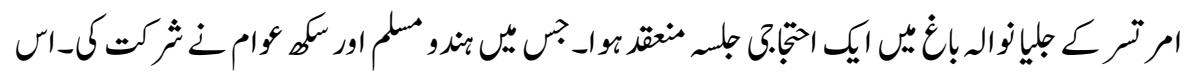

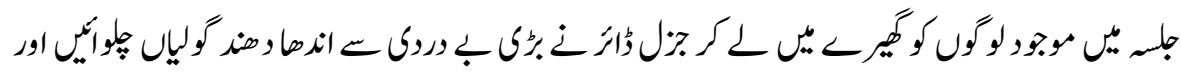

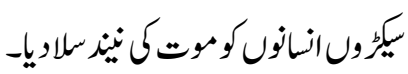

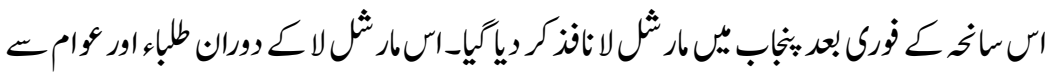

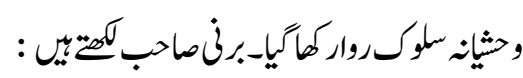

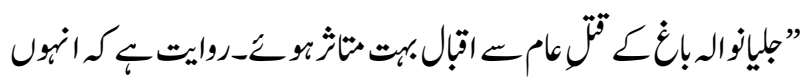

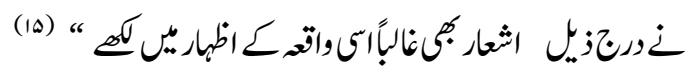

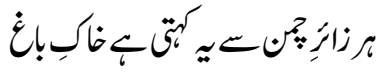

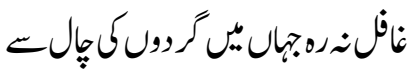

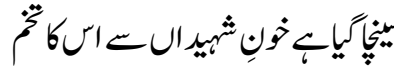

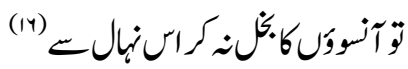




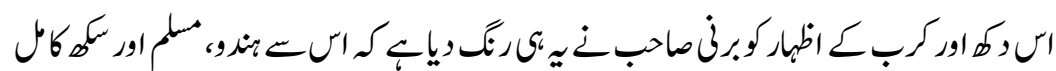

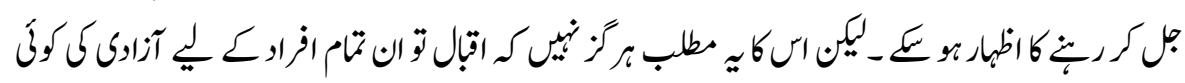

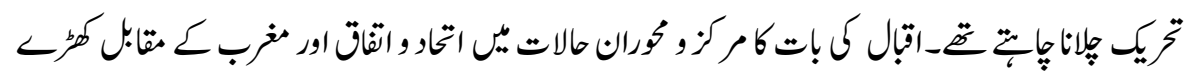

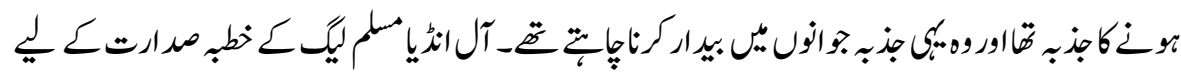

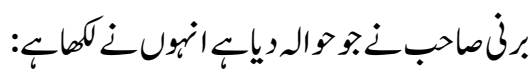

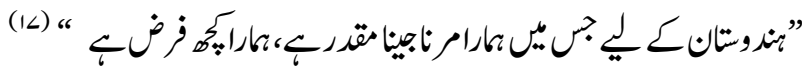

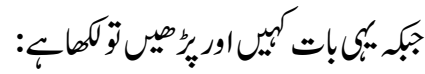

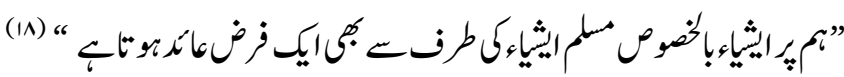

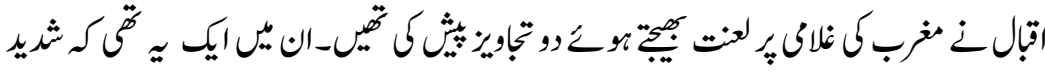

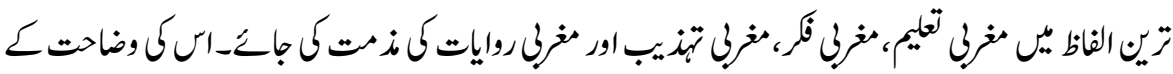

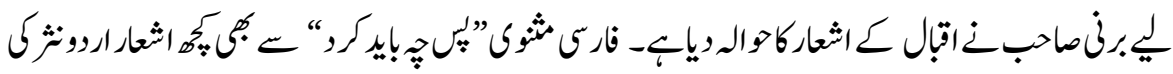

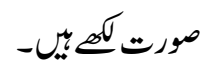

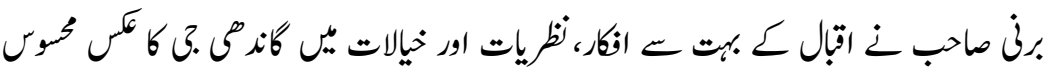

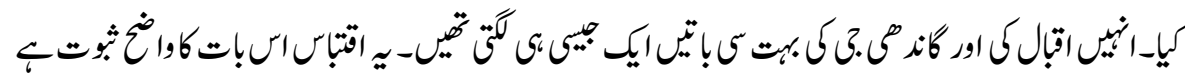

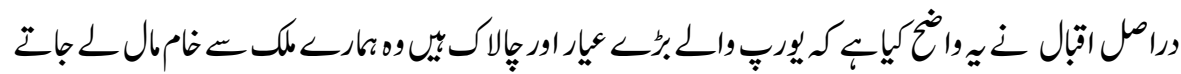

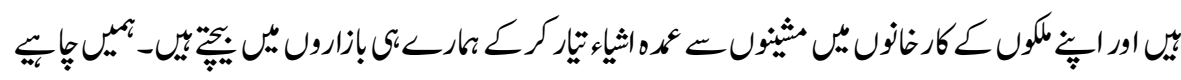

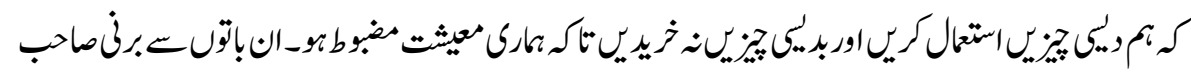
ذبي اخذكياب:

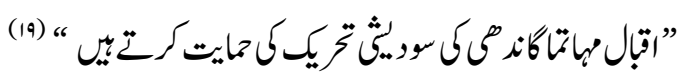

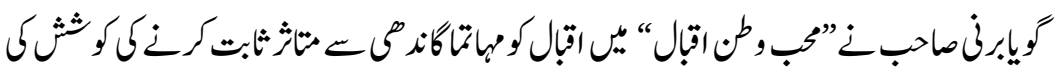

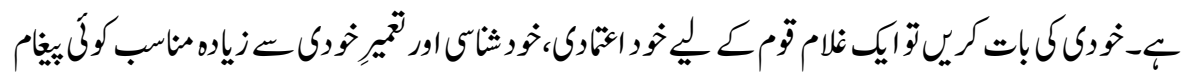

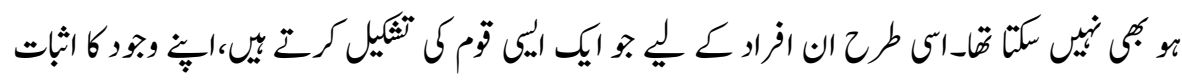




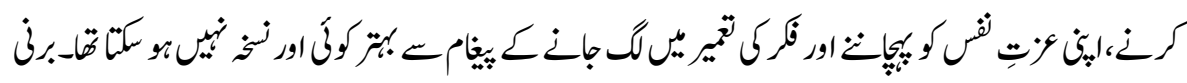
صاحب لكمتمبي:

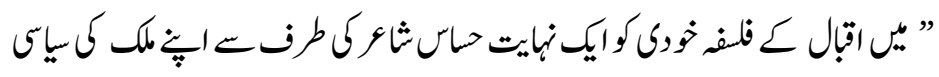

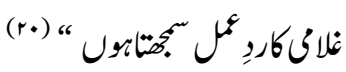

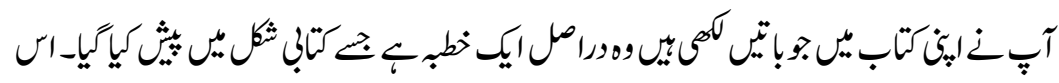

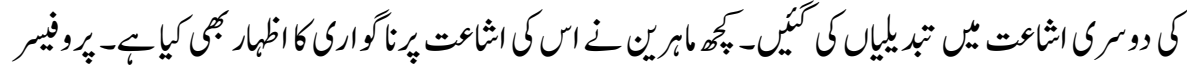
عبرانق فراتئي:

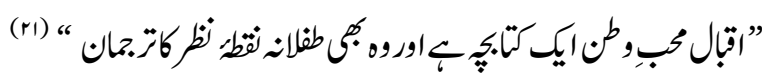

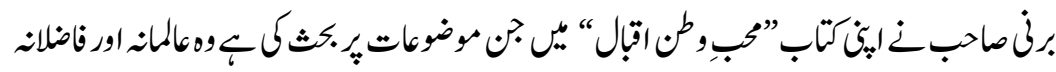

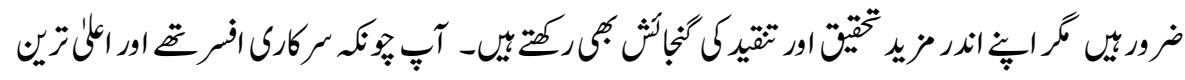

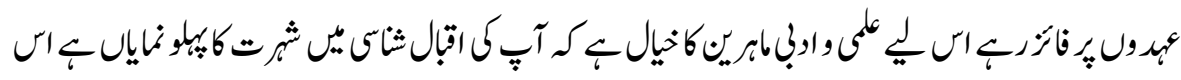

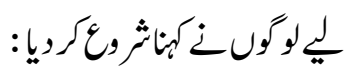

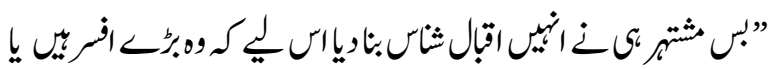

(rr) “ $\ddot{\tilde{E}}$

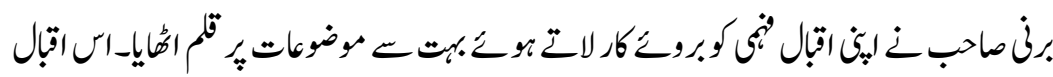

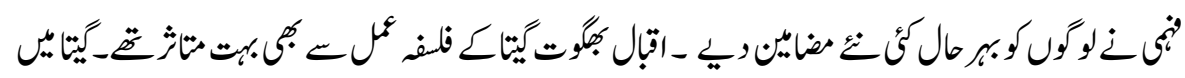

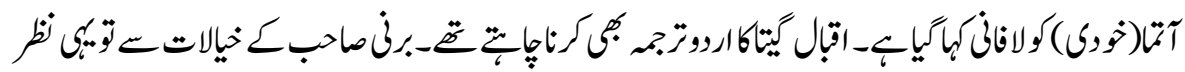

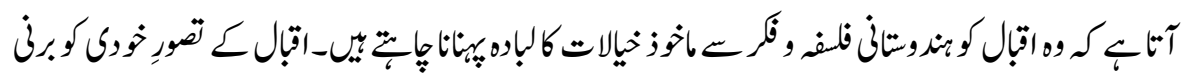

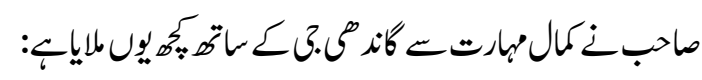

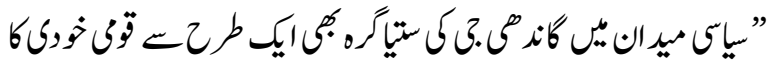

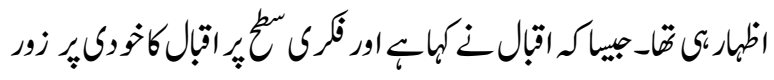

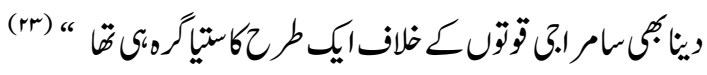




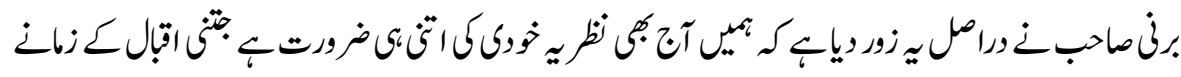

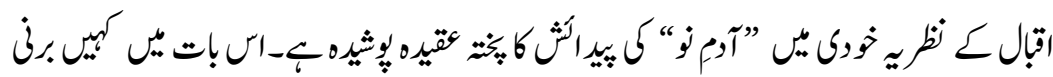

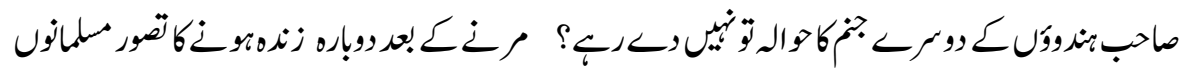

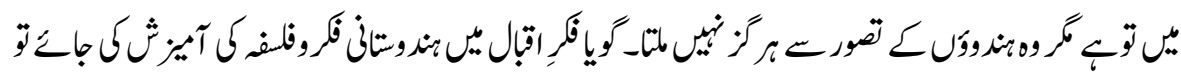

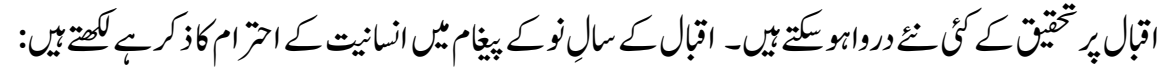

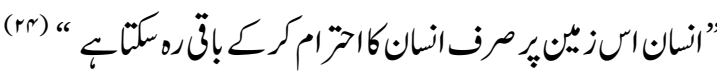

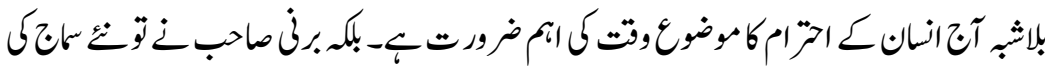

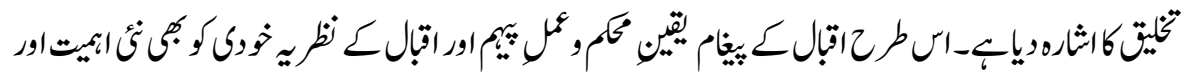

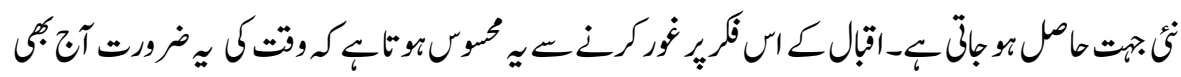

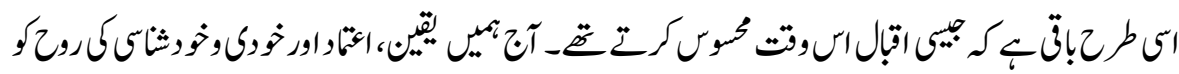

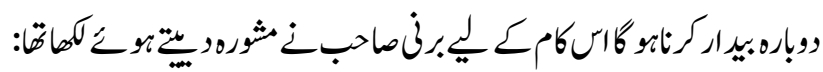

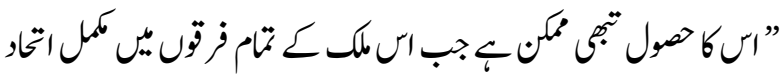

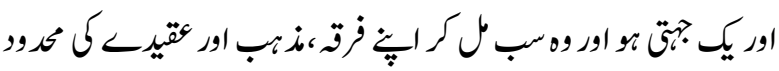

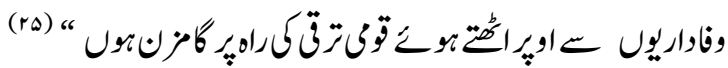

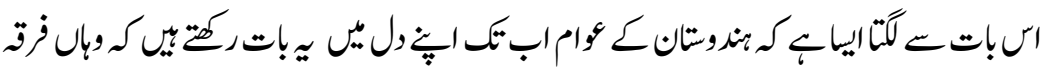

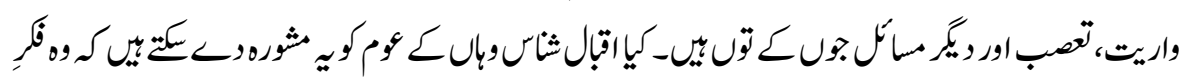

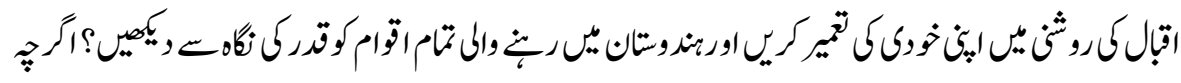

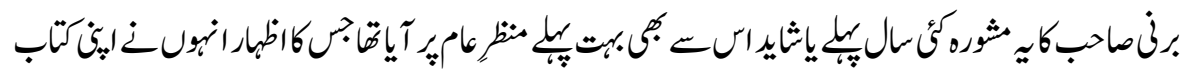

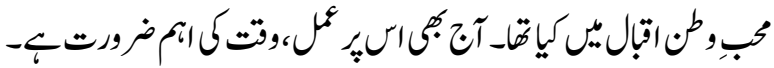

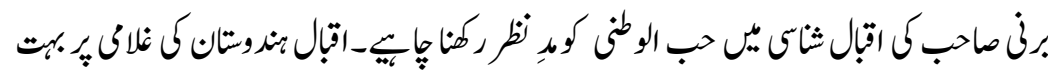

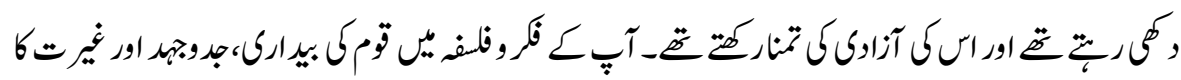

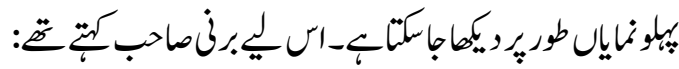




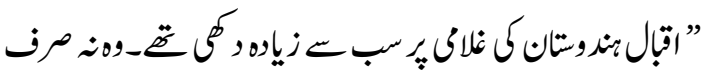

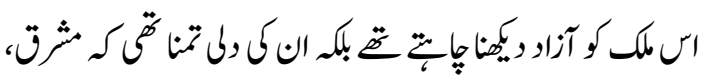

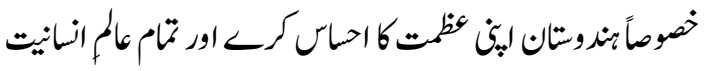

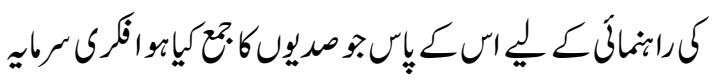

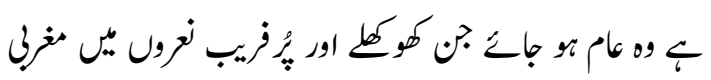

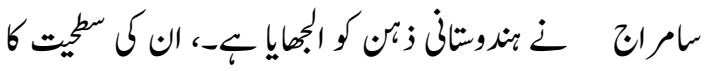

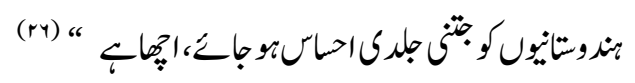

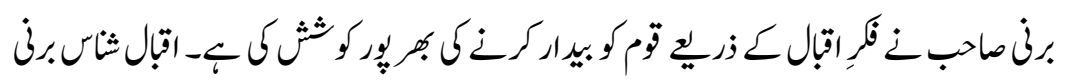

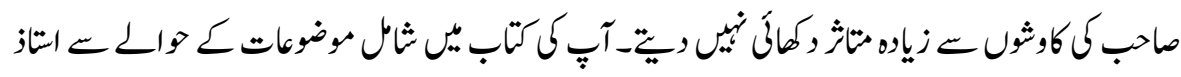

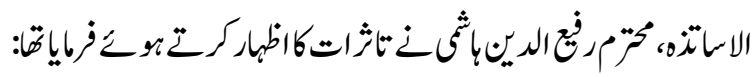

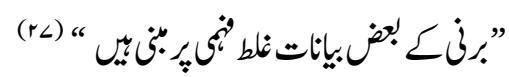

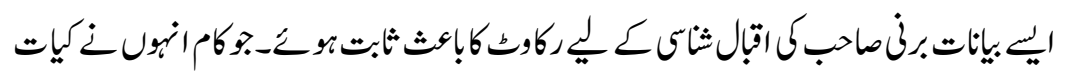

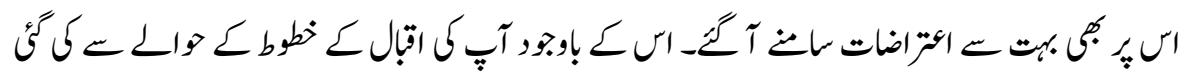

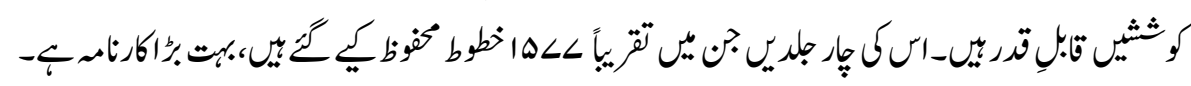

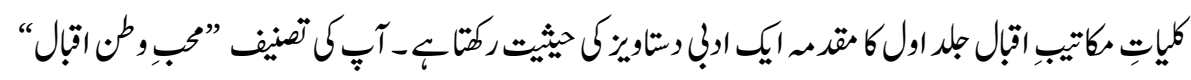

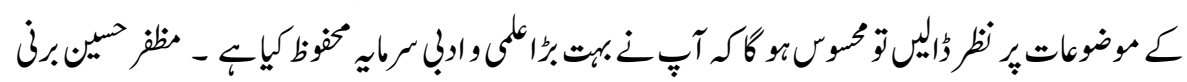

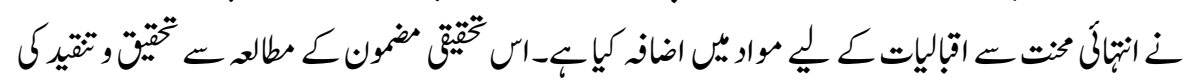

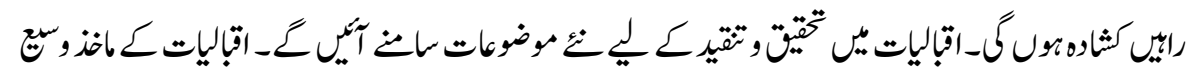

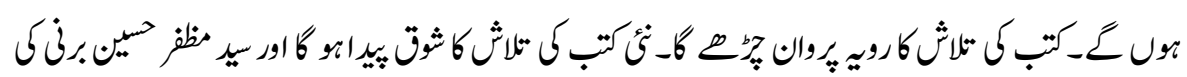

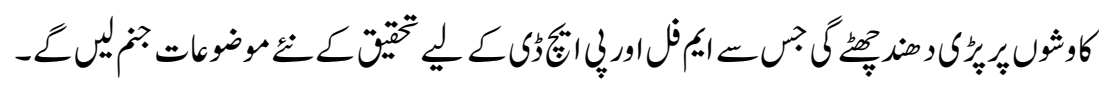
والرجات

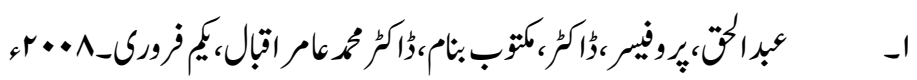




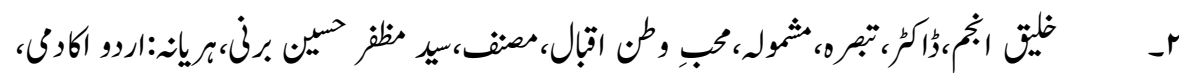

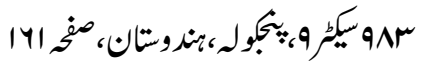

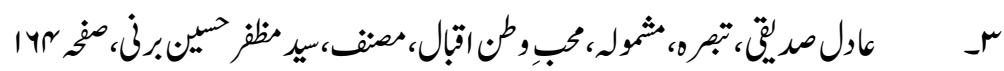

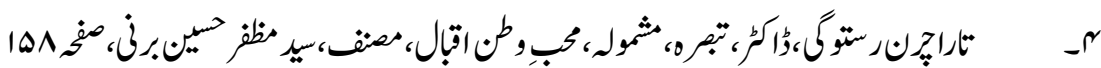

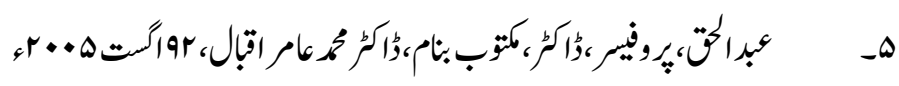

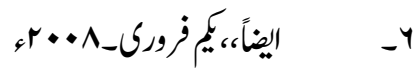

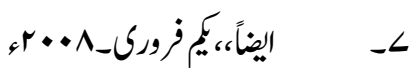

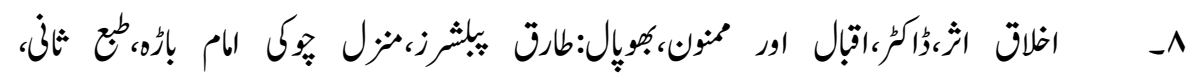
|ar

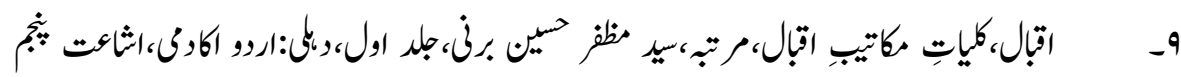

$$
\text { 1r. 19.999 }
$$

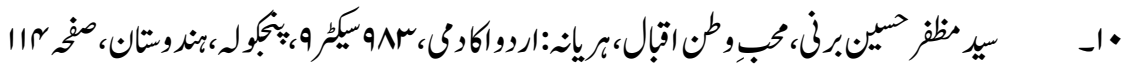

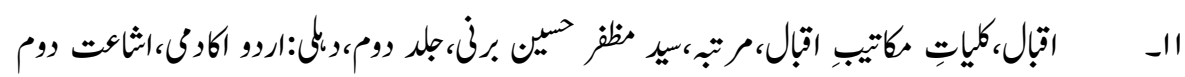

$$
\text { riY صن }
$$

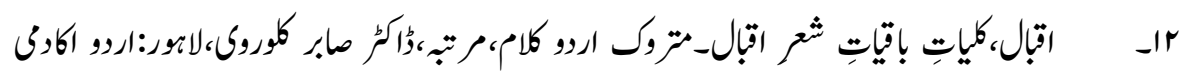

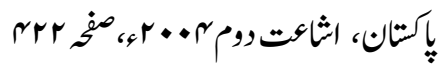

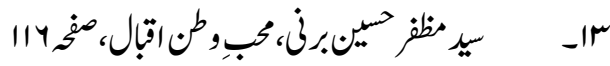

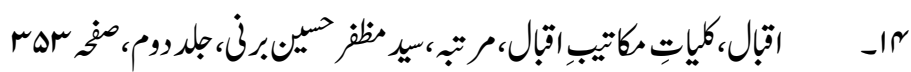

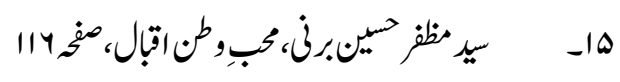

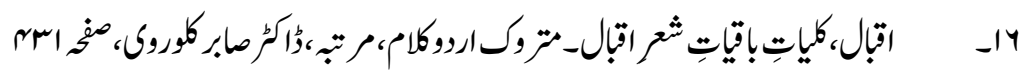

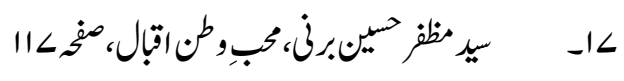

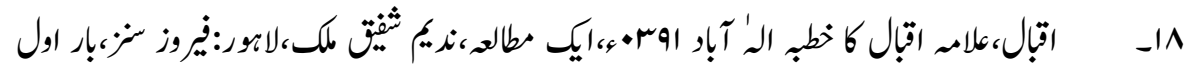

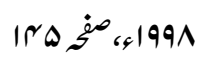




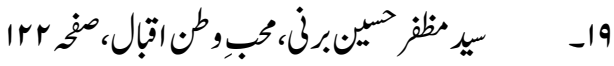

$$
\begin{aligned}
& \text { r r. }
\end{aligned}
$$

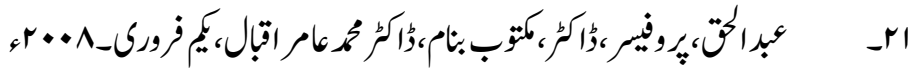

rr

rrr

Ir

ar

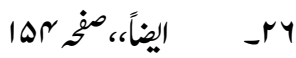

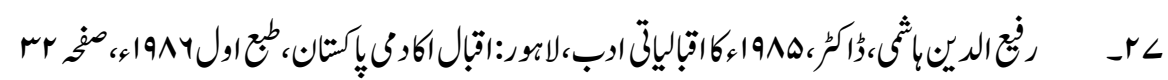

